\title{
ESI-MS for the measurement of bovine and porcine somatotropins
}

\author{
N. Rochut, B. Le Bizec, F. Monteau and F. André* \\ LDH/LNR, École Nationale Vétérinaire de Nantes, BP 50707, 44037 Nantes Cedex 3, France \\ * Corresponding author: andre@vet-nantes.fr
}

\begin{abstract}
Somatotropins are proteins naturally produced by the pituitary gland in cattle. Recombinant somatotropins, which differ from their native form by several amino acids, have been synthesised in order to increase milk production in dairy cows. As their use is forbidden in Europe, control has to be performed. Until now, radioimmunoassay methods were generally used for quantification, but none is able to distinguish endogenous from recombinant somatotropins. Herein, a sensitive method based on liquid chromatography-mass spectrometry (LC-MS) and electrospray ionisation (ESI) is presented in view to identify and quantify somatotropins in milk and plasma. Accuracy of the technique should allow the molecular mass differentiation between pituitary and recombinant somatotropins. The detection limit was measured at the nanogram level. As a second approach an enzymatic digestion was performed on recombinant somatotropin. A $\mathrm{N}$-terminal digest proved to be specific and would allow to differentiate recombinant and endogenous proteins. Separation and detection of peptide fragments by ESI-LC-MS appear to be promising.
\end{abstract}

\section{Introduction}

Somatotropin (or growth hormone) belongs to the protein family of somatolactogenic hormones, produced by the pituitary gland. Somatotropin is a 22000 Dalton (Da) polypeptide growth hormone that has a major influence on normal growth and lactation in mammals. It is a single polypeptide chain consisting of 191 amino acids. The amino acid composition varies considerably between species. Advances in recombinant DNA techniques made sufficient quantities of recombinant growth hormone available for the use as milk production enhancing agent. It has been known for many years that milk production in dairy cows can be increased by as much as $20 \%$ or more when circulating levels of somatotropin are increased through the administration of growth hormone [1]. As somatotropin is a protein, it cannot be taken orally, but has to be injected. Recombinant derived somatotropin products may have slightly different chemical structures from the natural somatotropin produced by the pituitary gland, by adding a number of amino acids on the $\mathrm{N}$-terminal side. The administration of recombinant porcine growth hormone has been shown to markedly improve growth performances and carcass characteristics by causing higher muscle mass and lower fatness [2]. Recombinant somatotropins, legally used in USA, are banned in Europe, nevertheless a watchfulness is required against the use of these substances. Therefore, methods are needed to differentiate the endogenous somatotropin from the recombinant ones. Recombinant bovine somatotropins look like the endogenous bovine growth hormone and are designed to exert the same effects in dairy cows. The risk of occurrence of undesirable residues, in edible tissues and milk, is potentially increased by the incidence of mastitis and others disorders and the rise of the use of veterinary medicinal products. The ability to reliably detect recombinant bovine somatotropins is important in living animals. Until now, the detection of growth hormone has been based on radioimmunoassays. Enzyme immunoassay procedure detects both natural and recombinant forms of bovine growth hormone in plasma [3]. The analytical methods used to determine growth hormone concentrations in plasma, milk and tissue of the animals were exclusively radioimmunoassay procedures and ELISA. None of them was able to distinguish between the endogenous and the recombinant growth hormone products [4-6]. Electrospray mass spectrometry has been used to determine the differences in term of molecular mass between natural bovine somatotropin and recombinant somatotropins [7]. Four variants exist for the natural bovine somatotropin with theoretical values from 21720 to 21796 Da. Although recombinant bovine somatotropin has been considered "essentially chemically the same as natural bovine growth hormone" [7], some specific differences should be mentionned: recombinant bovine somatotropins differ from the natural growth hormone by addition of 1 to 9 amino acids on the N-terminal. In most cases, the N-terminal alanine is replaced by methionine.

Here, high performance liquid chromatography coupled with mass spectrometry (LC-MS) has been chosen because of its high sensitivity and specificity for the studied molecules. The presented work consisted in the setting up of a measure method of somatotropin by LC-ESI(+)-MS. Two approaches were evaluated on somatotropin standards: 
- measurement of the exact mass of the protein;

- applicability of an enzymatic digestion in sight to reveal a characteristic peptic fragment in order to discriminate recombinant protein from the endogenous one.

\section{Experimental}

\section{Reagents and chemicals}

\section{Growth hormones}

Porcine somatotropin was obtained from Sigma (St Louis, MO, USA). Standard solutions were prepared at the concentration of $1 \mathrm{mg} / \mathrm{mL}$ in methanol. Working solutions were prepared extemporaneously and obtained by successive dilutions at concentrations from $100 \mathrm{ng} / \mathrm{mL}$ to $1 \mathrm{ng} / \mathrm{mL}$. All these solutions were kept in the dark below $-16{ }^{\circ} \mathrm{C}$. The protein concentrations of various growth hormones were measured using the Bradford protein assay [9]. As standard, bovine serum albumin (Bio-Rad, München, Germany) was used in concentration between $25 \mu \mathrm{g} / \mathrm{mL}$ and $500 \mu \mathrm{g} / \mathrm{mL}$. The purity of the recombinant bovine somatotropin preparations was checked by a sodium dodecyl sulfate-gelelectrophoresis.

\section{Solvents}

All reagents and solvents were of HPLC grade, except solvents used for infusion, which were of analytical grade. All were provided by Merck (Darmstadt, Germany) and Solvents Documentation Syntheses (SDS, Peypin, France). HPLC grade trifluoroacetic acid (TFA) was obtained from Sigma Chemicals (St Louis, MO). Deionized water (Milli-Q, Millipore Inc, Milford, MA) was used in all experiments.

\section{Trypsin and $\alpha$-chymotrypsin}

Trypsin, which had been treated with tosylamido-2-phenylethyl-chloromethylkenone (TPCK), and $\alpha$-chymotrypsin were from Sigma Chemicals (St Louis, MO). The digestion procedure for porcine and bovine somatotropins was previously described by Chang et al. [8]. Trypsin, prepared in a $100 \mathrm{mM}$ Tris-acetate buffer ( $\mathrm{pH} 8.5,1 \mathrm{mg} / \mathrm{mL}$ ) was added to the substrate in a ratio of 1 to $20(\mathrm{w} / \mathrm{w})$. The digestion was carried out at $25{ }^{\circ} \mathrm{C}$ for $20 \mathrm{~h}$. Samples were stored at $-20{ }^{\circ} \mathrm{C}$ until analysis. A similar procedure was performed for the $\alpha$-chymotrypsin digestion.

\section{HPLC}

An Alliance 2690 HPLC pump with quaternary gradient system and automatic injector was used (Waters, Milford, MA, USA). Reversed phase liquid chromatography was realised on octadecyl grafted silica Vydac $(250 \times 4.6 \mathrm{~mm}, 5 \mu \mathrm{m})$ stationary phase (Vydac, Hesperia, CA, USA) coupled with a guard column Vydac C18 $(10 \times 4.6 \mathrm{~mm}, 5 \mu \mathrm{m})$. Elution solvents were acetonitrile (ACN) (solvent A) and water containing $0.1 \%$ trifluoroacetic acid (TFA) (solvent B). The isocratic mode was applied on a mobile phase of acetonitrile/water and trifluoroacetic acid (60:40; v/v). Flow rate was $0.3 \mathrm{~mL}$.min and the injected volume was $10 \mu \mathrm{L}$.

\section{Mass spectrometry}

Electrospray data were acquired using a QuattroLC ${ }^{\circledR}$ triple quadrupole instrument (Micromass, Manchester, UK) in positive mode. Nitrogen was used as nebulisation and desolvation gas, at flow rates of 86 and $580 \mathrm{~L} / \mathrm{h}$ respectively. Source and desolvation temperatures were 120 and $220{ }^{\circ} \mathrm{C}$. Potentials applied on the capillary (from 2.5 to $4.0 \mathrm{kV}$ ) and on the cone (from 15 to $35 \mathrm{~V}$ ) were optimised for each analyte. Infusion experiments were done with solutions at $50 \mathrm{ng} / \mu \mathrm{L}$ in methanol/water/formic acid (50:50:1 v/v/v) with a $60 \mu \mathrm{L} / \mathrm{min}$ flow rate.

\section{Chromatographic separation of peptide fragments}

Chromatographic separation of digested fragments was conducted using the same HPLC as described above. Separation was achieved using a C18 column (Vydac, $25 \times 4.6 \mathrm{~mm}$, $5 \mu \mathrm{m}$ ) and a flow rate of $0.2 \mathrm{~mL} / \mathrm{min}$. The gradient used for this separation was acetonitrile (solvent $\mathrm{A}$ ) and water/trifluoroacetic acid $(1000: 1 \mathrm{v} / \mathrm{v})$ (solvent B). The percentage of $\mathrm{B}$ decreased from 40 to 5 over 25 minutes and increased up to 20 , over 20 minutes.

\section{Results and discussion}

\section{Mass spectrometry}

Electrospray ionisation-LC-MS has been selected because of its better efficiency for ionisation of proteins. The multiplicity of protonation observed under normal electrospray conditions is such that the electrospray spectra of proteins may be recorded in the $\mathrm{m} / \mathrm{z}$ range below $4000 \mathrm{Da}$; protein analysis is thus feasible on quadrupole mass filter. The exact molecular mass was obtained after maximum entropy and deconvolution processing of the recorded electrospray data. It was calculated from the individual multiply charged ions, as noted in figure 1 . The spectrum of recombinant bovine somatotropin, obtained after infusion, gave a molecular mass of $21871 \pm 4 \mathrm{Da}$, i.e. $151 \mathrm{Da}$ higher than the molecular mass of the endogenous bovine somatotropin. This technique is thus able to differentiate pituitary somatotropin and recombinant somatotropin according to Scippo et al. [7].

On one hand, infusion is the introduction way of choice when the analyte is highly purified or particularly concentrated. On the other hand, high performance liquid chromatography (HPLC) must be performed before any MS measurement in order to eliminate all background interferences especially when biological samples are analysed. 


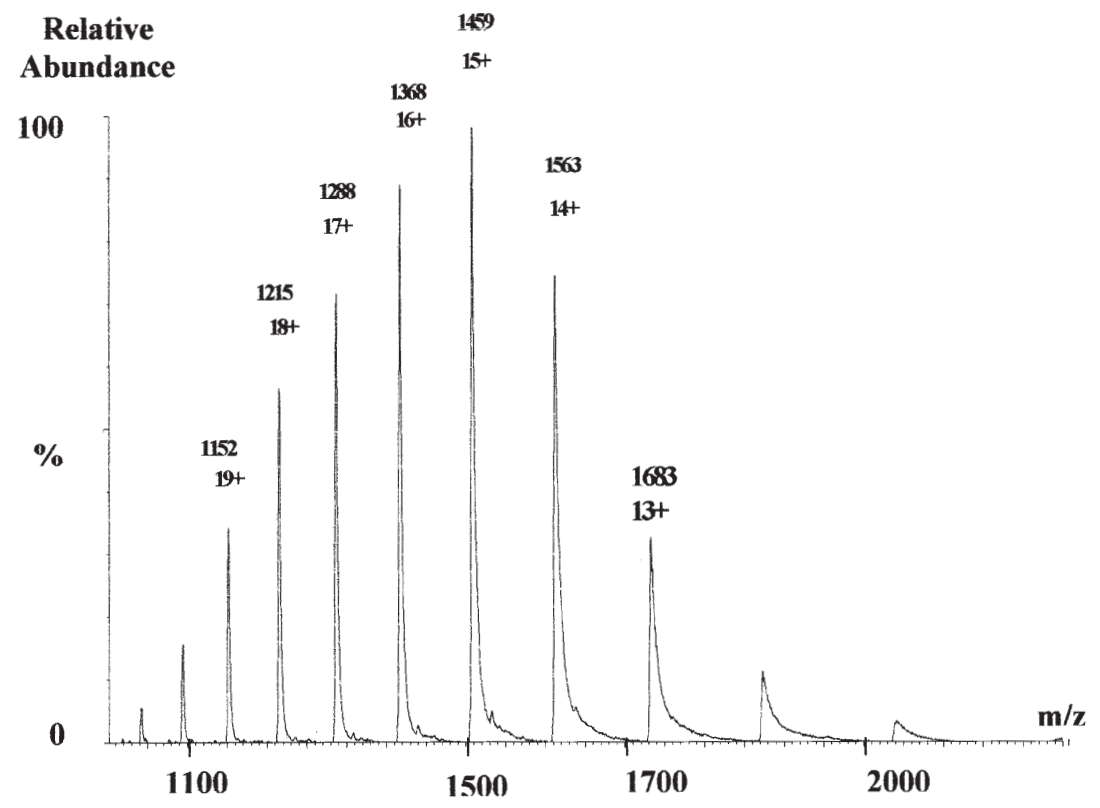

Figure 1. ESI + spectrum of recombinant bovine somatotropin (Lactotropin). Molecular mass measured at $21871 \pm 4 \mathrm{u}$. Conditions : $10 \mu \mathrm{g}$ of recombinant bovine somatotropin were infused in methanol/water/formic acid (50:50:1, v/v/v). Flow rate was set at $60 \mu \mathrm{L} / \mathrm{min}$.

A typical LC-MS chromatogram is shown in figure 2. It corresponds to the injection of $10 \mu \mathrm{g}$ of commercial endogenous porcine somatotropin. The ESI (+) mass spectrum of the protein exhibits a base peak with 15 charges in the conditions described before. The experimental molecular mass was about $22950 \pm 3 \mathrm{Da}$. The target value given by the commercial supplier at 22948.6 Da proved to be within the standard deviation of the experimental value. A minor protein was also detected in the Sigma preparation: its molecular weight was found at $21732 \pm 4 \mathrm{Da}$. It would be a second form or a degradation product of porcine somatotropin.

The LC-ESI (+)-MS method developed on somatotropin standards demonstrated its potential to measure the exact mass of $22 \mathrm{kDa}$ protein at worst $\pm 5 \mathrm{Da}$. The performance proved on standards would theoretically allow the differentiation between recombinant somatotropins and the endogenous one, the mass difference being at least $150 \mathrm{Da}$.

\section{Enzymatic digestion}

The second approach we evaluated was the enzymatic digestion of somatotropin, with the main objective to generate a specific peptide which is characteristic of the recombinant protein. This peptic fragment can then be identified by LCMS. Only the N-terminal sequencing of recombinant somatotropin and pituitary somatotropin is useful to study the ends of proteins. The study of the N-terminal extremity of somatotropins whatever their origins, could allow their identification.

Trypsin has been widely used as a digestion enzyme in peptide mapping due to its high specificity for cleavage at the C-terminal side of lysine $(\mathrm{K})$ and arginine $(\mathrm{R})$ residues. Extemporaneously prepared solutions of trypsin were used for all digestion procedures. The required incubation time

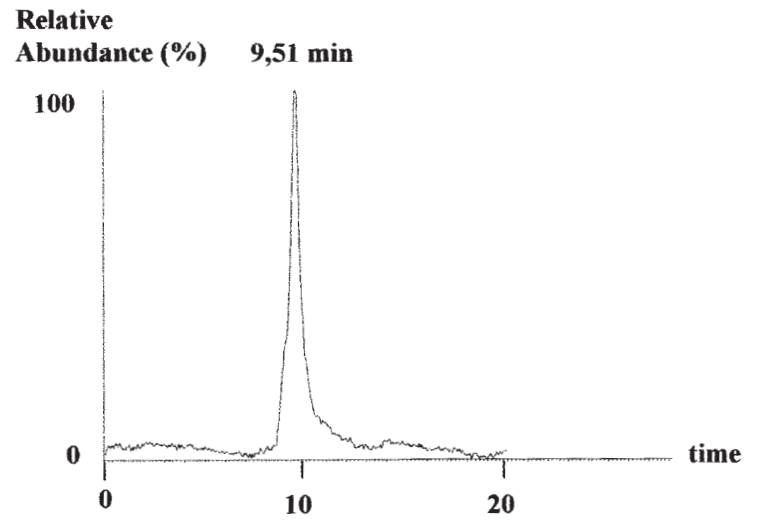

A.

Relative

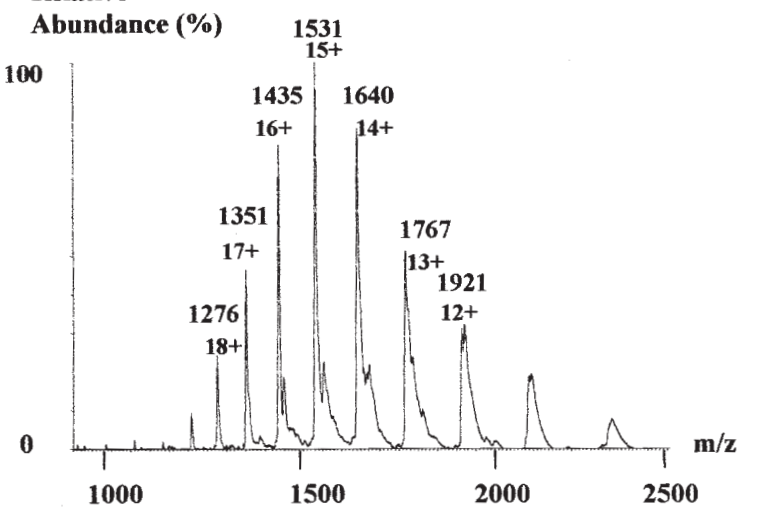

B.

Figure 2. Total ion chromatogram (A) and ESI + mass spectrum (B) of endogenous porcine somatotropin eluted at 9.51 minutes. Main protein occurred at $22950 \pm 3 \mathrm{Da}$. A minor protein was measured at $21732 \pm 4 \mathrm{Da}$. Acetonitrile/water/trifluoroacetic acid $(60: 40: 0.1, v / v / v)$ was used as mobile phase; flow rate was set at $0.3 \mathrm{~mL} / \mathrm{min}$. 
I.

\section{Relative} abundance

II.
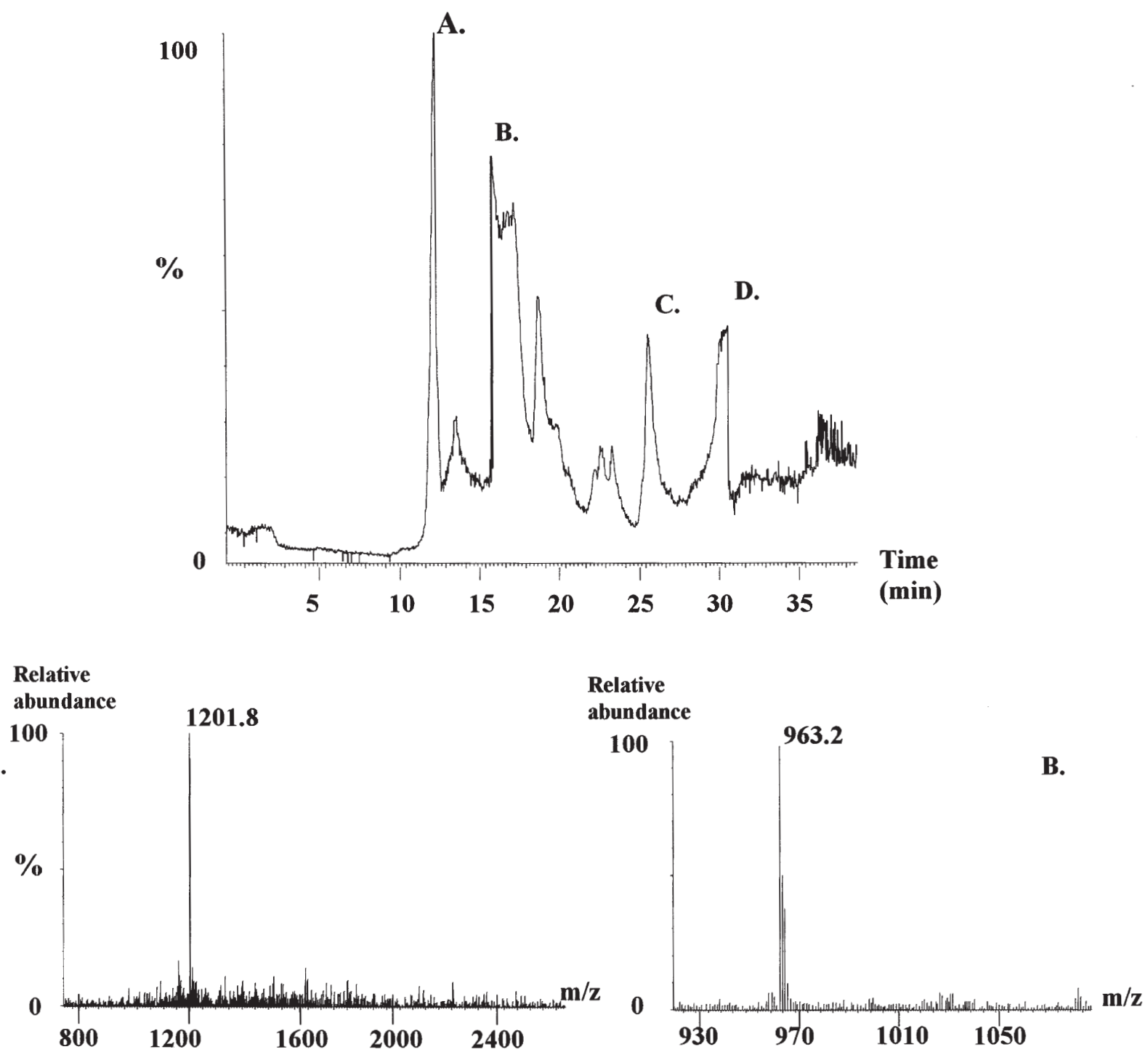

Relative

abundance
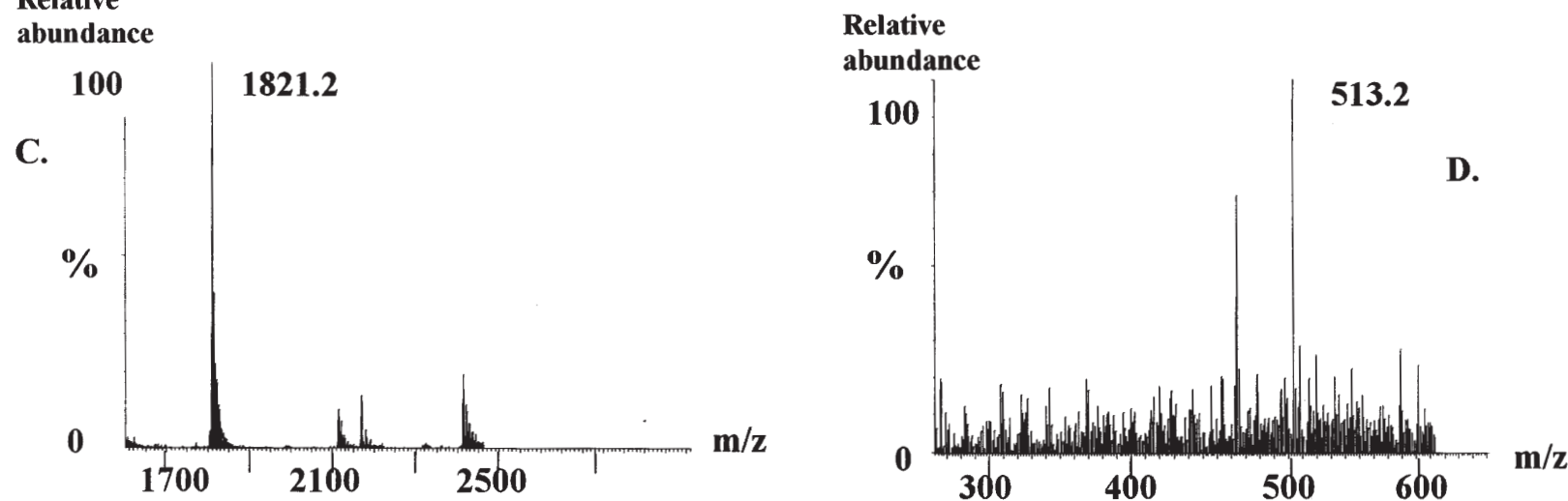

Figure 3. Total lon Chromatogram of tryptic digestion of recombinant bovine somatotropin (I) and mass spectra main fragments (II-A to D). Specific peptic fragment of recombinant bovine somatotropin occurred at 26.23 minutes (m/z 1821.2). The peptide fragments were eluted on a C18 column with a acetonitrile/water/trifluoroacetic mobile phase. 
was at least $20 \mathrm{~h}$ for porcine and bovine somatotropins to reach an efficient digestion.

In figure 3-I a complex total ion chromatogram (TIC) of digested recombinant bovine somatotropin can be observed and four main compounds are visible (peaks A to D). Their mass spectra are shown in figure 3-II; their molecular masses were measured at 2403.6 Da (doubled charged peptide), 913.2, 1821.2 and 513.2 Da for the compounds A, B, $\mathrm{C}$ and $\mathrm{D}$ respectively. According to the well-known structure of bST and preliminary results published by Chang et al. [8] we deduced the amino acid composition of these four peptic fragments:

- Peptide A: the 1201.8 Da fragment on figure 3-II-A corresponds to the $[\mathrm{M}+2 \mathrm{H}]^{2+}$ so the molecular mass is 2401.2 Da: YSIQNTQVAFCFSETIPAPTGK, amino acid sequence from 43 to 64 .

- Peptide B: m/z at 963.2: TYIPEGOR, sequence 35-42 is shown in figure 3 -II-B.

- Peptide C: $\mathrm{m} / \mathrm{z}$ at 1821.2: MFPAMSLSGLFANAVLR, amino acid sequence 1-17 presented in figure 3-II-C.

- Peptide D: $\mathrm{m} / \mathrm{z}$ at 513.2: DLHK, sequence 168-171 in figure $3-$ II-D.

Figure 3-II-C represents the specific peak of recombinant bovine somatotropin after enzymatic sequencing (called peptide C). In fact, the fragment appeared at 1821.2 Da, corresponding to the calculated sequence MFPAMSLSGLFANAVLR (amino acids from 1 to 17: $1823.9 \mathrm{Da}$ ). Digestion of pituitary bovine somatotropin would show a peak at 1674.7 $\mathrm{Da}$ instead of the one at 1823.9 Da because of the missing methionine residue. It would lead to a peptide characterised by a different retention time and molecular weight. In summary the detection of residue $\mathrm{C}$ (26.23 $\mathrm{min}, \mathrm{m} / \mathrm{z}$ 1821.2) promises to be a good diagnostic signal to discriminate recombinant somatotropins from its endogenous form, and consequently proves the illegal use of this molecule.

\section{Conclusion}

Two different methods based on LC-ESI-MS have been developed in order to detect unambiguously somatotropin treated cows. The first method is the direct detection of the exogenous somatotropin by the determination of accurate molecular masses of proteins. This study demonstrated the applicability of this approach because of the reliability in the mass measurement even at $22 \mathrm{kDa}$ (standard deviation better than $5 \mathrm{Da}$ ) compatible with the significative mass difference between endogenous and synthetic forms of somatotropin (at least $150 \mathrm{Da}$ ). The second method with protein digestion generated a specific peptide fragment for recombinant somatotropin (peptide $\mathrm{C}, \mathrm{m} / \mathrm{z}$ 1821.2) significantly different from the corresponding one obtained on pituitary bovine somatotropin $(\mathrm{m} / \mathrm{z} 1674.7)$. In spite of the insufficient clean up of the digest, this analytical strategy seems to be very promising and certainly more efficient and more suitable due to a higher sensitivity than the first approach. At this stage it is obvious that a specific method of extraction and purification needs to be developed from complex biological matrices (such as milk and plasma) as a clean-up step of tryptic digest before LC-MS analysis. Finally these results will have to be validated on animals after administration of different recombinant somatotropins in order to prove the applicability of this method and its robustness.

\section{Acknowledgements}

We would like to thank Pr. G. André-Fontaine and Dr. N. Ruvoen-Clouet for their kindly help in protein quantification and electrophoresis separation.

\section{References}

1. Bauman, D.E.; Eppard, P.J.; De Geeter, M.J.; Lanza, G.M. J. Dairy Sci. 1985, 68, 1352-1362.

2. Knorr, C.; Moser, G.; Muller, H. et al. Anim. Genetics 1997, 28, 124-128.

3. Brambilla, G.F.; Berrini, A.; Borromeo, V.; Secchi, C. Anal. Chim. Acta 1993, 275, 173-176.

4. Zwickl, C.M.; Smith, H.W.; Bick, P.H. J. Agric. Food Chem. 1990, 38, 1358-1362.

5. Hennies, M.; Holtz, W. J. Immunol. Methods 1993, 157, 149153.

6. Roh, S.G.; Matsugana, N.; Miyamoto, A.; Hidaka, S., Hidari, H. Endocr. J. 1997, 44, 195-198.

7. Scippo, M.L.; Degand, G.; Duyckaert, A.; Maghuin-Rogister, G. Ann. Méd. Vét. 1997, 141, 381-390.

8. Chang, J.P.; Kiehl, D.E.; Kennington, A. Rapid Comm. Mass Spectrom. 1997, 11, 1266-1270.

9. Bradford, M.M. Anal. Biochem. 1976, 72, 248-254. 